\section{Information Literacy: Past Approaches and Present Challenges}

\section{PENNY MOORE}

\section{Abstract:}

Interest in information literacy is increasing as the information age challenges educators to keep abreast of new developments in subject matter and technology. In this article, past approaches to teaching aspects of information literacy are reviewed and their implications for future learning and teaching are discussed. The role of collaboration between teachers and librarians is mentioned and information problem solving is examined as a context for developing thinking skills essential to information literacy. Professional development for both educators and librarians is seen as crucial to success in implementing the National Curriculum with respect to information skills.

\section{Introduction - Where Have We Come From?}

$\mathrm{T}$ he arrival of the information age is presenting educators and information professionals alike with many challenges. Some of those challenges arise from our past approaches to teaching information handling, others from advances in information technology itself. The efficacy of the national curriculum to support the development of essential skills will depend on how we choose to meet them.

Looking back, one realises that some aspects of education, in what are now called information skills, have not changed much at all. For instance, in terms of the curriculum, library and study skills have been taught in schools and colleges for nearly a century, but there still a gap between theory and practice (McKeachie, 1988; Marland, 1987). Librarians at the tertiary level can still be heard to ask why skills were not learned at school, and teachers can still be found who set assignments without appreciating the difficulties students encounter in researching them independently.

There have been several studies over the past decade that demonstrate that some students are leaving school unable, and in some cases unwilling, to find and use information independently (e.g., Reynolds \& Shirey, 1988; Rudduck \& Hopkins, 1984; Liesener, 1985), yet today the ability to access and use information is more important than ever. Even if we may not be directly involved in the information industry, the effects of the information explosion challenge us at every turn. Indeed, Weinstein and Mayer (1986) note that an increasingly important goal in education is that of "helping students develop effective ways to handle the barrage of information coming from the environment, as well as their own thinking processes" (p. 315). The challenge of meeting that goal will require an understanding of the cognitive demands of information handling and the specific contributions teachers and librarians can make to create contexts that support the development of metacognitive skills.

In the past, lessons in library and study skills have been divorced from the rest of the curriculum and the context of their application (Irving, 1985). They have often been assessed in terms of end-products such as essays and project reports. In general terms, responsibility for supporting their development has in fact been split between two professions - librarians helped students find information, and teachers helped them use it. The educative role of librarians, however, was not recognized and the cognitive aspects of information tasks were rarely addressed, largely because they have been hidden.

Information skills have been seen as the concern primarily of English language or humanities staff and have been taught at the classroom level as two quite separate entities - library skills, which ignored the relationship between thinking, communicating and finding information, and study skills, which ignored the need to identify, locate and evaluate which material is to be studied (Irving, 1985). While knowledge of these skills will be essential to information literacy in the future, there are additional elements that must be addressed, some of which will demand a different approach to both teaching and assessment of learning outcomes.

\section{The Present Situation}

Ann Brown (1994) has commented that enormous advances have been made this century in our understanding of learning and development, but school practices have not, in general, changed to reflect them. This opinion is supported with respect to information skills by a recent review by Rogers (1994). He found that the wealth of findings from information skills research in Britain has been slow and difficult to implement, 
particularly at the secondary school level. Similarly, in a review of study skills research, Schallert, Alexander and Goetz (1988) concluded that study skills courses have remained surprisingly isolated from findings obtained in training studies.

There appear to be at least two issues which must be addressed here. Firstly, while the individual components of information skills have received much research attention during recent years, little attention has been paid to how they are orchestrated in practice. The research literature frequently presents a view of the skills as discrete and non-interactive, yet this view is not supported if one watches what children actually do when they are involved in resource-based learning (Moore, 1995).

Secondly, critics have commented that teachers' awareness and skills in the area of information retrieval are poor (Liesener, 1985), while librarians have been said to be rather naive in their understanding of how information is used (Beswick, 1983). These perceptions again reflect the way in which information skills have been examined historically, in isolation from each other and from the context in which they are applied.

One challenge arising from these perceptions is to improve the information awareness of existing educators and to support their efforts to integrate information skills throughout the curriculum in more sophisticated ways. Basic teacher education has not emphasised the cognitive demands of coordinating information skills. It seems to have been assumed that previous school level tuition in library skills was sufficient and it was left to interested teachers to pursue their studies in aspects of librarianship alongside their teaching responsibilities. Few people hold dual qualifications in teaching and librarianship, and with the current pressure to choose between funding another classroom teacher or a qualified teacher librarian, there is little encouragement for teachers to extend their knowledge of the information profession at all.

At the same time, the degree of professional library support in schools, particularly at the primary level, has been abysmal. New Zealand schools have often had to rely on the voluntary support of parents to maintain school libraries, but the quantity of training available is poor.

\section{Pressures for Change - The Curriculum}

The introduction of a National Curriculum that includes information skills and a thread of technology in all subjects and at all levels demands that all teachers include them in their teaching. Yet some may never have developed their own skills in this respect and may lack an understanding of the complexities of information retrieval in general, or the confidence and computer literacy that underlie the use of information technology. Indeed, Chalmers and Slyfield (1993) found that more than two-thirds of teachers in New Zealand felt that they needed information skills training, particularly in relation to the use of information technology.

The issue of professional development needs to be addressed immediately, and on a continuing basis as technology changes, if the curriculum is to be delivered effectively and the tools of the information world are to be used for educational purposes. Yet practising teachers are already overloaded with curriculum changes, assessment procedures and increasing administrative tasks. Is there room for anything more?

The evidence from Britain is that the introduction of a national curriculum increases demands on library staff and resources. New opportunities emerge for teachers and librarians to work collaboratively, and the perceived role of libraries appears to be changing to a tool for supporting the curriculum and promoting cross-curricular themes and skills (Heeks \& Kinnell, 1994). This is an exciting development that has potential to result in school libraries moving to a central position in the curriculum and education, but it does demand that one recognise that teachers and librarians have complementary sets of skills and expertise that can benefit students.

There are of course several ways of approaching the situation. Librarians could be encouraged to take a more strongly educative role in schools, but for that to be accepted by educators, librarians' training will have to include more visible attention to teaching, child development and learning theory. At present in New Zealand there is no national qualification for children's librarians, let alone school librarians, yet as changes in teaching methods and greater familiarity with information technology impact on students, demands on school and public library services are likely to increase.

Teacher education, on the other hand, could include more emphasis on how information is organised, accessed and used, and how libraries and other information services can be used to enhance educational outcomes.

In the past, the links between learning theory, children's development and the curriculum have been difficult to expose in the context of the library, partly because of people's perceptions of the role of libraries in education and the difficulty of actually monitoring the learning that libraries support at an individual level. Norman Beswick observed in 1983 that libraries are assumed to be "admirable and essential, but are rarely shown to be so." It was not, at that time, clear how the presence of a school library could foster the development of informed and skilled 
reading, let alone the critical thinking and problem-solving skills that are seen as desirable today. Advances in learning theory and technology can be used to clarify that relationship.

\section{Pressures for Change - Technology}

In recent years some of the most significant changes in education have resulted from developments in information technology. Those developments are changing the way we think about intelligence and what we demand of education. For example, an increasing number of students are involved in coordinating concepts and skills from several subject areas to solve real-world problems (Dede, 1989). Such learning activities are promoting greater emphasis on collaborative learning, and the technology itself attracts educators who may previously have shown little interest in the information world.

There is, however, a note of caution to be sounded here. Not everyone realises that information technology is merely a tool and is no substitute for sound tuition in information problem solving. Most educators are well aware that information technology is allowing access to vast amounts of published knowledge in a variety of forms. The point remains that however sophisticated and easy to use the technology becomes, one still has to be able to comprehend, create a structure for, and integrate information from a variety of sources if it is to be transformed into personal knowledge.

In view of the wealth of information available, educators and librarians must ensure that students are very discerning in their use of information retrieval tools. Students need to select the most appropriate source for their purpose, be it electronic, paper or personal contact, and regardless of the format of the information gathered, they need to be able to do something with it. This implies a need for a range of literacies and critical assessment of not only the content of the information, but also of its mode of presentation.

One aspect of this particular challenge was captured rather neatly by Colin McGeorge when he said that, "time was that the information presented to children in schools came into the classroom either between the teacher's ears or in textbooks, charts and maps clearly labelled 'for educational use'" (McGeorge, 1988, p. 14). Now teachers have a bewildering array of materials and formats from which to choose. The ability to assess items in terms of informational accuracy and clarity, and appropriateness to the children's development, as well as the purpose of the educational task, thus becomes complex. In addition, when students are encouraged to carry out independent research tasks, teacher control over the quality and conceptual level of material accessed is reduced.

To echo Betty Cleaver (1986), the acquisition of effective information skills for both teachers and students may require a conceptual awareness of the nature of information and its diversity. At present a child searching a library independently may not locate materials that match reading ability and levels of existing knowledge, so as to ensure easy comprehension of the new material. That situation is compounded exponentially as information technology allows easy access to materials at expert level. The school librarian has a role to play in guiding children and teachers to appropriate sources, as well as in contributing to their understanding of the nature of information systems.

As Dede (1989) observed, the mostimportant barriers in the evolution of learning activities based on technological capabilities are not to be found in the technology itself; rather they centre on more fundamental conceptual and organisational issues. Information technology and the organisation of information systems have a high profile in the current education of librarians, but not in that of teachers. Collaboration would therefore seem sensible.

\section{Pressures for Change - Learning Theory}

As stated earlier, students have been taught library and study skills for nearly a hundred years, yet educators seem to have been ineffective in helping them translate those lessons into efficient independent practice. While most students have at some time or other been taught about library organisation, many have not received instruction in study skills at all. Indeed, McKeachie (1988) comments that in general students "stumble on effective study skills only when, by chance, they vary their approach and find that one method works better than others" (p. 5). Yet these are the very skills which embody structuring and organising information, analysing and critically evaluating it for consistency and accuracy, and integrating information from various sources.

At one time these complex thinking skills were seen as the preserve of society's educational elite, but they are now seen as desirable, if not essential, for all students (Resnick, 1987). Resnick points out that mass education derives from a low literacy tradition aimed at producing minimal competence in the general population. The information society demands that mass education now aims for a much higher standard of literacy over a wider range of media and modes of delivery. Thus to meet current demands, we need not only to repair the omissions of past teaching, but to go beyond them. 
So what has learning theory to offer that will help us meet these challenges?

\section{The Cognitive Demands of Information Problem-Solving}

Once it was assumed that complex thinking can only occur once children have reached some special stage of development - that one could add it on to more basic thinking abilities. Resnick makes the point that, "the most important message of modern research on the nature of thinking is that the kinds of activities traditionally associated with [higher order] thinking are not limited to advanced levels of development" (p. 10). Instead, when initial levels of learning are going well, the learner is likely to be engaging in quite sophisticated thinking. Increasing knowledge of the topic and experience of procedures and processes affords further advances in thinking complexity.

Resnick has described these higher order thinking skills as involving:

- "nuanced judgement and interpretation";

- the application of multiple criteria, some of which may be in conflict;

- self regulation of the thinking process;

- imposing meaning or finding structure in apparent disorder.

These skills are also

- non-algorithmic - that is the path of action is not fully specified in advance.

- They are complex - the total path cannot be seen (mentally speaking) from any single vantage point.

- They often yield a variety of solutions rather than a single right answer; thus there is a need to evaluate outcomes.

- They are however, effortful - the elaborations and judgements needed are mentally demanding.

The parallels between this description and what we understand from our own attempts to find and use information are fairly obvious. Further Resnick's suggestion is that to promote the development of thinking skills such as problem solving, reasoning and critical evaluation, we should concentrate our efforts on those aspects of the curriculum that enhance independent learning. Tasks involving information problem solving and resource-based learning meet this criterion extremely well. For example, watching 11-year olds handling books in libraries demonstrates that much thinking is made public during information searches as the decisions to be made influence the path and outcomes of information problem solving. Judicious questioning reveals children's perspectives on library layout, individual resources, the task of finding information and constructing knowledge from what is found, thus providing insights and points for discussion of processes that are often overlooked because of their covert nature (Moore \& St. George, 1991; Moore, 1995). When one analyses the knowledge areas and thinking processes revealed, two characteristics stand out.

Firstly, the tasks of identifying and defining a need to seek information, and following right through to satisfaction of that need, cannot logically be separated into discrete entities labelled library and study skills. Not only is the process continuous, but something more is required because the outcome of each phase of the process influences which phase will follow and what can be achieved in subsequent phases. For example, it was found that the way Year 6 children articulate their need for information more often than not dictated their choice of keywords for searching the catalogue. These keywords were used to help decide which books should be taken off the shelf and then applied to the contents tables and indexes. Some of the children knew that they should think of alternative words at some point in this process, but their knowledge of the topic was insufficient to allow flexible use of vocabulary, and their understanding of the demands of searching made them uncertain of when and how to change the focus of search terms. Thus the materials they found were not always the best for the task, and that limited the sort of knowledge structures they could build (Moore, 1995).

When it came to reading the texts, children often had very clear expectations about the format of appropriate answers to their specific questions, and if the match was not exact they didn't quite know what to do. For example, one girl wanted to know where albatrosses live. She located relevant information quite quickly, but said she couldn't get "a proper answer to that because they live in all different places." Instead of including a range of places, her final report simply said "They live at sea"! She apparently expected a one-line answer and a straightforward path to its location. She had no idea that the information itself could be used to enrich her conceptualisation of the question. The question in this case provided a solid framework for every activity that followed.

The second characteristic that stands out in analysis of children's thinking in this context is that independent information retrieval and use demands sophisticated thinking skills and flexible coordination of many areas of knowledge, together with an ability to monitor just where one is in the overall problem. This is no mean feat. For instance, as one searches 
for information on a subject, the notion of what is relevant constantly changes as one's knowledge base increases. Thus the efficient information-seeker constantly engages in assessment of knowledge to hand and revises the focus of the information search. This sort of knowledge assessment usually goes on covertly, but it can have dramatic effects on how information searching continues.

The dynamics of the information problem-solving process are illustrated in Figure 1, which highlights the role of self-questioning at every phase of the task. Dependent upon the answers to those questions, a learner may redefine the original information need, select a different form of information resource, look in several locations within a library, decide enough information has been gathered and begin to read for notetaking purposes or even ask for help.

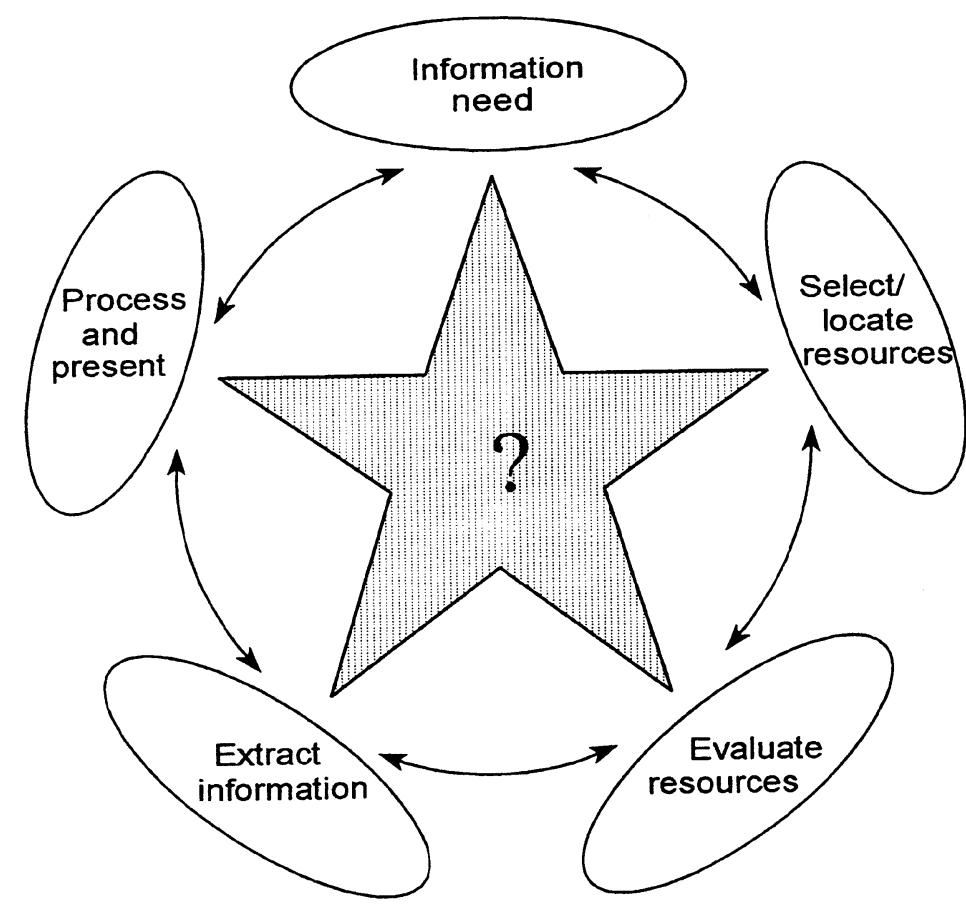

Figure 1 The information problem-solving process
In Moore's study, one boy in particular demonstrated the power of such dynamic thinking. Kieran claimed to know very little about birds, but seemed to know a great deal about the process of finding and using information. He identified a duck, the grey teal, as a species of interest in the first book selected and left this open on the floor. When he failed to find grey teal quickly in the next book he suddenly returned to the first one "because it might be a rare bird or something - I don't know if it is or not." This information had to be extracted from the first source to determine which chapter should be searched in the second. He also returned to that first book sometime later as he encountered a book on the shelf with the title Small Birds. This time he searched the text for details of the bird's size and on finding that it was $52 \mathrm{~cm}$ long, held his hands a part and concluded "That's pretty big for a bird!" Small birds was therefore not taken off the shelf.

This boy used every cue from the physical environment and every cue from his own thinking processes to guide his action in answering his original questions. The result was something more than one would expect from traditional descriptions of library and study skills. Indeed, every time Kieran failed to find an item in his mind or on the shelf, he engaged in problem-solving behaviours.

The majority of the students observed did not demonstrate his level of understanding of the demands of retrieving information from a library system. In most cases students were not aware that their search strategies could be at fault or could be changed. The overwhelming impression was that these students came to the task with a simple rule in mind: think of questions, identify keywords in them, search the catalogue for those words, get a Dewey number and when you get to the shelf, the book will be there. This impression was borne out to the extent that some students stated quite clearly that there would be one book for each Dewey number and that all books on a given topic would be at a single location. When their expectations were not met students often lacked ways of progressing on the task.

\section{Managing the Learning Situation}

To step back from the information task for a moment and look at the larger picture, it was evident that these 11-year olds often did not have access toinformation that would help them manage the learning situation to advantage. For instance, they did not seem to realise that the way learning is to be assessed has implications for one's choice of learning strategy. They had been given an appalling instruction - basically, do a 
project on birds - but, despite making it as easy as possible to challenge this, only 5 of 23 children asked anything about what that meant. In contrast, some of the insights about the implications of their learning abilities for selection of materials were quite shrewd. One boy said, for instance, that he preferred books with an index that has large letters at the beginning of each section, because he doesn't know his alphabet well.

What are the implications here for the curriculum of the future? Information skills are now embedded in the curriculum, and we recognize the need for them to be taught as an integral part of subject matter. Ross Todd and Celeste McNicholas, for instance, have provided strong empirical evidence of the benefits of this in terms of learning outcomes (Todd, 1994). They have shown that opportunities to engage critically with information, even information as old-fashioned as nursery rhymes, can promote the very thinking skills that are seen as essential to living in an information society. What we also need is to make students aware of the dynamic nature of information searching and how this affects specific learning outcomes.

Some features identified in Moore's study will remain with us regardless of technological advances. Indeed, other researchers have expressed the view that the knowledge needed for accessing electronically stored information is inseparable from that needed for information-seeking in a print-based system (Fasick, 1995). The essential features of both types of system can be described in terms of the relationships between four sets of variables. Those relationships have important implications for creating learning contexts that support the development of higher-order thinking skills and for instruction in information skills.

First, consider the nature of the students and what they bring to any learning task in terms of knowledge, attitudes, purpose and abilities. Next, consider the learning activities themselves. Different learning activities make different cognitive demands on students, have different learning outcomes and demand particular materials. The materials themselves make cognitive demands on students too, not only in terms of content, but also by what they assume the student already knows, the way they structure and present concepts, and the way they are organised both physically and intellectually. Finally, learning in schools always carries with it an element of assessment, and assessment tasks similarly make cognitive demands on students (and not always those expected).

Expert learners know something about each of those sets of variables and the relationships between them. They can select materials appropriate to their existing level of knowledge and their present purpose. They can gauge the demands of an assessment task and choose the learning strategy that best suits their personal learning style and the nature of the exam or test to follow. In other words, they manage the information coming from the environment and their own thinking processes (Brown, Bransford, Ferrara \& Campione, 1983).

Changing the focus on that same set of variables and relationships lets educators and librarians appreciate some of the things to be considered in setting up learning contexts in which information skills will be enhanced. There are implications here for the types of learning activities we set and the way we assess the outcomes, for the skill building and background knowledge necessary before children can work independently, and for the nature of the feedback given learners.

When it comes to using information technology, educators need to think about the cognitive demands it makes on students as well as the exciting opportunities it has to offer. It is only through understanding those that an appreciation will arise of what sort of instruction will be needed to compensate for the inherent difficulties of using tools designed primarily for adults, and how best to bend the technology to educational goals.

Liesener (1985) has commented that before one can hope to teach higher-order thinking skills, a more sophisticated view of information and information users is needed. It is also suggested that our understanding of children as information users needs to be expanded. While much of the literature describes information retrieval and use from the adult viewpoint, little focuses on the children's view, yet their levels of understanding of information systems and the resources within them constrain their ability to apply sophisticated thinking skills and to learn independently.

\section{Summary and Conclusion}

Earlier, the view of Weinstein and Mayer (1986) was quoted, that one of the most important goals for education is to help students develop effective ways to deal with the barrage of information coming from the environment and from their own thinking processes. This coincides well with the definition of information literacy as the ability to effectively access and evaluate information from multiple sources to meet the specific needs of the student.

While technology may change the format and complexity of the information that students can access and work with, the development of information literacy and the ability to interpret and manage the outputs 
of one's own thinking processes remain tied to issues in learning theory and human development.

Specific attention to the thinking skills underlying information retrieval and use meets educational goals in several areas of the curriculum: promotion of information skills; problem solving and other higher order thinking skills; and technological understanding. This fourpronged approach to defining the educational purpose of school libraries provides a strong foundation for the journey into the future. However, it does rest on professional development for teachers and librarians and their ability to integrate the skills and knowledge of two professions for the benefit of children. Failure to meet these professional development needs will result in failure to ensure adequate educational use of advances in the information world now and in the future.

Technology is forcing us to consider the library without walls, maybe the virtual school library, and it may be that in this context people will be more readily able to conceive of the library in terms of an intellectual entity, a place where thinking skills are applied in every activity. The implication for the school library is that it becomes the major vehicle for the explicit development of sophisticated thinking skills in every area of the curriculum. That concept, combined with advances in information technology, will change the very fabric of education and school librarianship.

\section{References}

Beswick, N. (1983). The controversial school library: A critical reassessment and proposed new strategy. Education Libraries Bulletin, 26(2), 1-15.

Brown, A. L. (1994). The advancement of learning. Educational Researcher, 23(8), 4-12.

Brown, A. L., Bransford, J. D., Ferrara, R. A. \& Campione, J. C. (1983). Learning, remembering and understanding. In P. H. Mussen (Ed.), Handbook of developmental psychology. (3rd Ed.), Vol. 3, pp. 77-141. New York: Wiley.

Chalmers, A. \& Slyfield, H. (1993). Contributions to learning: Libraries and New Zealand schools. Wellington: National Library of New Zealand, Research Unit.

Cleaver, B. P. (1987, Fall). Thinking about information: Skills for life long learning. School Library Media Quarterly, 29-31.

Dede, C. (1989, September). The evolution of information technology: Implications for the curriculum. Educational Leadership, 23-26.
Fasick, A. (1995). Children's use of information technology. In Allen Kent (Ed.) Encyclopaedia of Library and Information Science, 55(18), 51-69. New York: Marcel Dekker.

Heeks, P. \& Kinnell, M. (1994). School libraries at work. Library and Information Research Report, 96. London: British Library.

Irving, A. (1985). Study and information skills across the curriculum. London: Heinemann Educational.

Liesener, J. (1985, Fall). Learning at risk: School library media programs in an information world. School Library Media Quarterly, 11-20.

Marland, M. (1987). Libraries, learning and the whole school. Emergency Librarian, 15(2), 9-14.

McGeorge, C. (1988). Report of the working party to review the school library service. Wellington: National Library of New Zealand.

McKeachie, W. J. (1988). The need for study strategy training. In C. E. Weinstein, E. T. Goetz \& P. A. Alexander (Eds.), Learning and study strategies. San Diego: Academic.

Moore, P. A., \& St. George, A. (1991). Children as information seekers. School Library Media Quarterly, 19(3), 161-168.

Moore, P. A. (1995). Information problem-solving: A wider view of library skills. Journal of Contemporary Educational Psychology, 20(1), 1-31.

Resnick, L. B. (1987). Education and learning to think. Washington, DC: National Academy Press.

Reynolds, R. E. \& Shirey, L. L., (1988). The role of attention in studying and learning. In C.E. Weinstein, E. T. Goetz \& P. A. Alexander (Eds.), Learning and study strategies. San Diego: Academic.

Rogers, R. (1994). Teaching information skills: A review of the research and its impact on education. London: British Library.

Rudduck, J. \& Hopkins, D. (1984). The sixth form and libraries. Library and Information Research Report 24. London: British Library Research and Development.

Schallert, D. L., Alexander, P. A., \& Goetz, E. T. (1988). Implicit instruction of strategies for learning from text. In C.E. Weinstein, E. T. Goetz \& P. A. Alexander (Eds.), Learning and study strategies. San Diego: Academic.

Todd, R. (1994). Integrated information skills instruction: Does it make a difference? School Library Media Quarterly, 23 (2), 133-138.

Weinstein, C. E. \& Mayer, R. (1986). The teaching of learning strategies. In M. C. Wittrock (Ed.), Handbook of research on teaching (3rd ed.) pp. 315-327. New York: McMillan. 


\section{The author}

Penny Moore is currently a research manager at the Open Polytechnic of New Zealand. She has previously lectured in both the Teacher Education and Library and Information Studies Departments of Victoria University of Wellington. This article is based on an invited address to the Australian School Libraries Association 14th Biennial Conference held in Fremantle, October 1995. 